\title{
Brief survey: Determining brain death in Canadian intensive care units
}

\author{
[Enquête ponctuelle : la détermination de la mort encéphalique dans les unités de \\ soins intensifs au Canada]
}

Christopher James Doig MD MSc, Kimberly Young RN BSN, † Jeannie Teitelbaum MD, $\ddagger$ Sam D. Shemie MD\$

Purpose: Criteria for brain death were first described in 1968, and Canadian guidelines were published in 1988. However, international inconsistency persists in the process of determining brain death. We sought to determine self-reported practices and processes in the determination of brain death amongst Canadian intensive care unit (ICU) physicians.

Methods: An email survey of members of the Canadian Critical Care Society was undertaken. A survey instrument was developed, then face and content validated prior to distribution.

Results: Eighty eight responded (response rate $=49 \%$ ), including adult and pediatric ICU physicians working in both tertiary referral (academic) and community hospitals. Most respondents admit patients with brain death to their ICUs. However, $9 \%$ reported refusing to admit this type of patient for reasons including inappropriate utilization of ICU resources (36\%), and lack of either space or staff (32\% and $29 \%$ of respondents, respectively). Community hospital-based ICU physicians were less likely to report a hospital policy on the determination of brain death $(46 \%$ vs $78 \%$ of physicians in tertiary care hospitals). Nearly all physicians $(96 \%)$ reported that a revised national standard and checklist for the determination of death would be useful.

Conclusions: Nearly one quarter, and over one half of tertiary care and community hospitals (respectively) in Canada lack an institutional policy on neurological determination of brain death. Canadian ICU physicians are interested in a national standard for the determination of death, and establishment of processes that may improve the clinical determination of death by neurological criteria.
Objectif: Les critères de mort encéphalique ont été décrits en 1968 et des directives canadiennes publiées en 1988. Un manque de cohérence internationale persiste dans le processus de détermination de la mort encéphalique. Nous voulions définir les pratiques auto-évaluées et les processus de détermination de la mort encéphalique parmi les médecins des unités de soins intensifs (USI) au Canada.

Méthode : Un formulaire d'enquête électronique $a$ été envoyé aux membres de la Société canadienne de soins intensifs. Un instrument d'enquête a été élaboré, puis la présentation et le contenu ont été validés avant la distribution.

Résultats : Les 88 répondants (49\%), travaillaient dans des USI pour adultes et des USI pour enfants d'hôpitaux tertiaires (universitaires) et communautaires. La plupart acceptent dans leur USI des patients dont la mort encéphalique a été déclarée. Mais 9 $\%$ refusent de le faire pour des raisons comme l'utilisation inappropriée des ressources de I'USI (36\%) et un manque d'espace ou de personnel ( $32 \%$ et $29 \%$ des répondants respectivement). Les médecins d'hôpitaux communautaires ont été moins nombreux à rapporter de politique institutionnelle de détermination de la mort encéphalique (46\% vs $78 \%$ des médecins d'hôpitaux de soins tertiaires). Presque tous les médecins (96\%) ont mentionné qu'il serait utile de réviser les normes nationales et la liste récapitulative à utiliser pour la détermination de la mort.

Conclusion : Près d'un quart, et plus de la moitié, des hôpitaux tertiaires et communautaires (respectivement) au pays manquent de politique institutionnelle sur la détermination neurologique de la mort encéphalique. Les médecins d'USI sont intéressés à des normes nationales et à l'établissement de processus pouvant améliorer la détermination clinique de la mort selon des critères neurologiques.

From the Departments of Critical Care Medicine, Medicine, and Community Health Sciences, ${ }^{*}$ Faculty of Medicine, The University of Calgary, Calgary, Alberta; the Canadian Council for Donation and Transplantation; $\dagger$ the Department of Neurology, $\ddagger$ Montreal Neurological Institute, McGill University, Montreal, Quebec; and the Division of Critical Care Medicine, Department of Pediatrics, $\$$ Montreal Children's Hospital, McGill University Health Centre, Montreal, Quebec, Canada.

Address correspondence to: Dr. Christopher James Doig, Associate Professor, Rm EG23G Foothills Medical Centre, 1403-29 ${ }^{\text {th }}$ Street

NW, Calgary, Alberta T2N 2T9, Canada. Phone: 403-944-1691; Fax: 403-283-9994; E-mail: cdoig@ucalgary.ca

Accepted for publication August 12, 2005.

Revision accepted January 16, 2006.

Final revision accepted January 17, 2006.

Competing interests: None declared. 
I N 1968, the Ad Hoc Committee of the Harvard Medical School published a seminal report on the neurological criteria to determine death (brain death). ${ }^{1}$ The concept of death by neurological rather than cardiopulmonary criteria has been adopted widely since that time. However, there remains considerable international variation in the clinical criteria or processes for determining death based upon neurological criteria. ${ }^{2}$ In Canada, guidelines were published in $1986 .{ }^{3}$ In 1999 , a small committee of neurocritical care specialists updated these guidelines. ${ }^{4}$ We undertook a national survey of Canadian intensive care unit (ICU) physicians to determine the variability in use of clinical criteria to diagnose brain death. A secondary objective was to explore if available ICU resources might affect brain dead individuals becoming organ donors.

\section{Methods}

In 2003 we conducted an email survey of critical care physicians practicing in Canadian ICUs. The study sample was identified from members of the Canadian Critical Care Society $(n=277)$ who had a valid email address $(n=178)$. Prior to the survey, an information letter was sent to all participants, followed by the survey form $48 \mathrm{hr}$ later, two reminder emails seven and ten days later, and a follow-up phone call at two weeks. Surveys were only accepted if received within four weeks of the initial mailing. In accordance with Research Ethics board requirements at the institution of the primary author, informed consent was not obtained, as return of the survey was considered as assent, and the survey did not include personal identifying information.

The survey was developed by the authors for the sole purpose of this study, and conducted by Decima Research Inc. (Toronto, ON, Canada). Face and content validity were assessed by circulating the questionnaire to a select group of experts in the fields of neurosciences $(n=5)$, and survey design $(n=5)$ at the institution of the primary author. Comments on the syntax and structure of the questions were obtained from individuals at Decima Research Inc. who have considerable experience in conducting surveys of this type. Finally, the survey was field tested on a small sample $(n=10)$ of ICU physicians in the intended target population. Feedback on content and construction of questions was incorporated prior to distribution of the survey. Testing of the criterion and construct validity assessment of the survey were not undertaken. The survey development and study design did not include examining testing or variable-response reliability such as test-retest, inter-rater or internal consistency computations.
An administrative assistant independent of the research team was designated to receive all completed surveys, and stripped 'sender' email addresses from the responses prior to forwarding the surveys for collation and analysis. Data are presented in the form of simple descriptive statistics.

\section{Results}

The Canadian Critical Care Society included 277 members, of whom 178 had valid electronic mail addresses available at the time of the survey. The response rate was $88 / 178(49 \%)$. Of the respondents, $77 \%$ identified themselves as working in adult ICUs, and $79 \%$ worked in university affiliated urban referral ICUs, $12 \%$ in urban community hospitals, $7 \%$ in non-university urban referral hospitals, and $2 \%$ in non-urban community hospitals. Ninety-five percent of represented ICUs had more than 11 beds, of which $42 \%$ had 11 to 20 beds, and $53 \%$ had more than 20 beds. Three-quarters $(76 \%)$ of pediatric and $84 \%$ of adult ICUs had 11 or more beds. All non-university ICUs were less than 20 beds in size. The respondents reported that they cared for surgical patients $(96 \%)$, medical patients $(94 \%)$, neurosurgical patients $(77 \%)$, cardiac surgical patients $(46 \%)$, and organ transplant recipients $(46 \%)$.

The survey responses are summarized in the Table. Eighty-nine percent of respondents reported that patients presenting to their emergency department with severe brain injury and a poor anticipated neurological outcome are always, or usually admitted to the ICU for a trial of therapy and prognostication. Intensive care physicians caring for pediatric patients (86\%) always admit patients with these presentations, compared to ICU physicians caring for adult patients who reported always, $(20 \%)$ or usually (64\%) admitting this type of patient. Nine percent of respondents reported that they had at least once refused admission or transfer of patients with severe brain injury and poor neurological outcome. The most common responses for refusing admission were: 1) inappropriate utilization of ICU resources - not otherwise defined $(48 \%) ; 2$ ) lack of physical bed space $(20 \%) ; 3)$ lack of ICU staff $(20 \%) ; 4)$ family declined admission (15\%); and 5) patient not deemed a suitable candidate for organ donation (9\%). Patients assessed in the emergency department and determined to be brain dead were reported as always admitted to ICU for the purpose of organ donation by $51 \%$ of respondents, and usually admitted, by $34 \%$ of respondents. The main reasons for not admitting a case of brain death to ICU were: 1) perceived inappropriate use of resources - not otherwise defined $(36 \%) ; 2)$ lack of physical ICU 
TABLE Summary responses regarding brain death determination

\begin{tabular}{ll}
\hline & $\begin{array}{c}\text { Responses } \\
(n=88)\end{array}$ \\
& \\
\hline $\begin{array}{l}\text { Management and admission of brain injured patients } \\
\text { Admit these patients to ICU }\end{array}$ & $40 \%$ \\
Always & $51 \%$ \\
Usually & $51 \%$ \\
Admit cases of expected brain death & $34 \%$ \\
Always & $20 \%$ \\
Usually & \\
Institution has a policy on admission of these patients & \\
& \\
Institution has a written policy on brain death (yes) & $74 \%$ \\
Adult ICU & $62 \%$ \\
Pediatric ICU & $78 \%$ \\
Academic/tertiary ICU & $46 \%$ \\
Community ICU & \\
& \\
Institution policy is followed & $65 \%$ \\
Always & $33 \%$ \\
Usually & $1 \%$ \\
Seldom & $2 \%$ \\
Don't know & \\
Tools for the diagnosis of brain death would be & \\
somewhat or very useful & \\
Standard national definition & $96 \%$ \\
Checklist of elements & $94 \%$ \\
Process to report brain death & $67 \%$ \\
Seminar/training lessons & $56 \%$ \\
Legislated definition & $48 \%$ \\
Usual method of documenting brain death & $48 \%$ \\
Notation in medical chart & \\
Formal institutional checklist & \\
Medical certificate of death & \\
\hline ICU = intensive care unit. The response rate for all questions was \\
100\% of respondents.
\end{tabular}

bed space $(32 \%) ; 3)$ lack of ICU staff $(29 \%) ; 4)$ not a suitable candidate for organ donation $(6 \%)$; and 5 ) admission declined by family (4\%).

Most physicians (73\%) reported that their institution has a policy regarding determination of brain death. It was more common for physicians in a tertiary care hospital to have a policy than a physician at a community hospital (78\% vs 46\%). Of physicians reporting that their institution has a policy, 65\% reported they always follow the policy, and 33\% reported they usually follow the policy. These results did not vary by type of hospital, size of ICU, or patient type (adult or pediatric). Most physicians (96\%) reported that a national standardized definition of brain death and checklist of elements would be useful. Despite this result, only just over half considered training sessions necessary, and just under one-half considered legislation on brain death necessary. The majority of physicians (adult $82 \%$, pediatric $100 \%$ ) document brain death by a notation in the patient's chart. A checklist is used by some physicians (adult 50\%, pediatric 35\%). Just under half of physicians also document this information on the death certificate, although no province formally requires this information, or collates this data. Twenty-four percent of physicians report that their ICU collects data on the incidence of brain death.

\section{Discussion}

This survey describes self-reported patterns of practice of ICU physicians in Canada relating to the process of care of patients with severe brain injury who progress to brain death. Why is this important? The Harvard Ad Hoc Committee's seminal report on brain death criteria described the need to establish a process, in part, to prevent controversy in obtaining organs for transplantation. ${ }^{l}$ Public surveys have identified the important link between the public's confidence in the determination of death, and the willingness to donate organs for transplantation purposes. Although families do not always conceptually understand brain death, the willingness to donate organs in part reflects the great trust and confidence in the medical profession, reasonably inferred that practices about the determination of death, end-of-life care, and organ donation are similar between physicians and hospitals. ${ }^{5}$

This survey found that most physicians agree with the concept of a national non-legislated standard for the determination of brain death, and tools such as 'checklists of elements' may help. Our survey did not ask why such checklists would be helpful: for example, to ensure the correct criteria were used, or to standardize documentation of the process used. However, previously published Canadian criteria for brain death may be applied inconsistently. ${ }^{6}$ This problem is not unique to Canada. In 1995, Mejia and Pollack reported the variability of practice in pediatric ICUs. ${ }^{7}$ Identified variations include a lack of apnea testing in $23 \%$ of cases, "controversial" apnea testing in $22 \%$ of cases, and other "contradictory" practices. Bell et al. recently conducted a survey in the United Kingdom of neurocritical care experts, and found similarly variable practices. ${ }^{8}$ Finally, Keogh and Akhtar reported omissions in the documentation of the clinical criteria for brain death in medical notations in the chart. ${ }^{9}$ In those centres which used checklists, clinical criteria omissions were significantly lower. These 
authors suggested that documentation on a checklist would be beneficial. Standardizing the processes (criteria and documentation) for determining brain death may be crucial to maintaining public confidence in these important medical decisions.

This survey was only intended to be descriptive, and there are several limitations which must be considered. The sampling frame identified only intensive care physicians who are members of the Canadian Critical Care Society. Use of a professional society is common surveying physician practices, although all physicians who work in Canadian ICUs may not be members of this society. Furthermore, this survey was limited by a response rate of only $49 \%$. However, responses were received from all regions of the country, from physicians who practice in different clinical settings (i.e., community to tertiary-academic hospitals), from physicians who see different types of ICU patients (for example medical, surgical, neuro-critical, and trauma), and from different sized ICUs. Although nonresponse is a potential bias of any survey, the diversity of clinical practice represented by these respondents decreases the likelihood of this type of systematic error affecting these study results. Finally, only the face and content validity of the survey was examined. However, as the purpose was only to describe certain attitudes in ICU physicians, and given the lack of data or prior hypotheses in this area, we felt that our approach to not proceed with construct or criterion testing was reasonable.

This survey does demonstrate variability in some processes of care in the determination of brain death, and the likelihood of admission to an ICU. Although our survey is limited by a response rate of $49 \%$ albeit a response rate similar to other studies - there is reasonable support amongst ICU physicians for the development of a national standard for the neurological determination of death, and a standard process, such as by checklist, for documenting these clinical findings. A consensus conference to facilitate such a standard may help maintain and foster the public's confidence in the determination of death by neurologic criteria, and requests to families to consider organ donation.

\section{References}

1 Anonymous. A definition of irreversible coma. Report of the Ad Hoc Committee of the Harvard Medical School to Examine the Definition of Brain Death. JAMA 1968; 205: 337-40.

2 Wijdicks EF. Brain death worldwide: accepted fact but no global consensus in diagnostic criteria. Neurology 2002; 58: 20-5.
3 Anonymous. Death and brain death: a new formulation for Canadian medicine. Canadian Congress Committee on Brain Death. CMAJ 1988; 138: 405-6.

4 Anonymous. Guidelines for the diagnosis of brain death. Canadian Neurocritical Care Group. Can J Neurol Sci 1999; 26: 64-6.

5 Hazony $O$. Increasing the supply of cadaver organs for transplantation: recognizing that the real problem is psychological not legal. Health Matrix Clevel 1993; 3 : 219-57.

6 Shemie S, Teitelbaum J, Doig C. Variability in hospitalbased brain death guidelines in Canada. Can J Anesth 2006; 53: 613-19.

7 Mejia RE, Pollack MM. Variability in brain death determination practices in children. JAMA 1995; 274: 550-3.

8 Bell MD, Moss E, Murphy PG. Brainstem death testing in the UK-time for reappraisal? Br J Anaesth 2004; 92: 633-40.

9 Keogh AT, Akhtar TM. Diagnosing brain death: the importance of documenting clinical test results. Anaesthesia 1999; 54: 81-5. 